\title{
La necesidad de compartir la ciudad con otros organismos vivos supusieron un cambio de paradigma en la relación del ser humano con el entorno natural ENTREVISTA COM JOSÉ IGNÁCIO AGUIRRE
}

\author{
Entrevistador: \\ Fabio Angeoletto \\ fabio_angeoletto@yahoo.es \\ Universidade Federal de Mato Grosso, Rondonópolis, MT
}

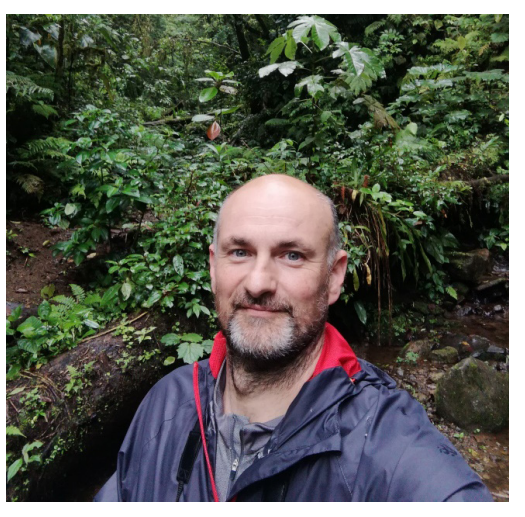

Dr. José I. Aguirre es Profesor Contratado Doctor en el Departamento de Biodiversidad, Ecología y Evolución de la Facultad de Biología de la Universidad Complutense de Madrid. Su investigación se ha basado en aspectos relacionados con la Biodiversidad Urbana. Ha estudiado la biología y la ecofisiología de aves urbanas utilizando como modelo el gorrión común y como contexto las metodologías aplicadas a través del Programa de Seguimiento de Biodiversidad del que es coordinador. Otro aspecto que ha abordado es el de las interacciones entre el comportamiento individual, las historias vitales y la dinámica de poblaciones. Ha combinado con éxito, la teoría y el seguimiento a largo plazo de individuos marcados. También ha trabajado en métodos analíticos para determinar el efecto de los contaminantes en la naturaleza y el uso de organismos vivos como bioindicadores, utilizando como modelo para ello la cigüeña blanca.

jaguirre@ucm.es

Terr@Plural - La Ecología Urbana tuvo un gran impulso, tanto en número de científicos, como en conocimiento producido, a partir de 1990. ¿Cómo definiría usted esta ciencia?

A partir de los años 90 del siglo pasado, la comunidad científica comenzó a tomar consciencia no sólo de la irreversibilidad del proceso de urbanización sino de la creciente tendencia a concentrar gran parte de la población humana en zonas urbanas.

Este fenómeno, unido a evidencia incuestionable del cambio climático y su muy difícil reversión hicieron considerar a la comunidad científica de que, la influencia de estos entornos en los procesos biológicos, lejos de ser anecdóticos, suponían un fenómeno creciente, interesante y digno de ser estudiado para extraer conclusiones y tendencias para el futuro.

En todo este proceso, el ser humano, es contemplado no sólo como un elemento más del ecosistema sino como el principal promotor, actor y responsable de los procesos naturales que tienen como escenario, los ecosistemas diseñados por y para su uso exclusivo. La necesidad de compartir estos entornos con otros organismos vivos y la exigencia de una coexistencia supusieron un cambio de paradigma en la relación del ser humano y las ciudades con el entorno natural. 
Terr@Plural -Los datos apuntan que, a pesar de las megaciudades, la mayor parte del crecimiento urbano, en términos globales, ocurre en ciudades pequeñas y medianas, cuya capacidad de planificación y gestión es usualmente baja. ¿Está usted de acuerdo con este punto de vista? ¿Y cómo la Ecología urbana puede ser aplicada para disminuir los impactos de esas urbes y para aumentar la calidad de vida de sus ciudadanos?

A pesar de que las megaurbes concentran un gran porcentaje de la población urbana, su superficie es proporcionalmente pequeña comparada con el resto de territorio disponible. Sin embargo, la concentración humana en ciudades pequeñas y medianas ya existentes hace que, aunque poco se puede hacer en cuanto a la planificación original, aún queda mucho que decir por parte de la comunidad científica en cuanto a sus planes de crecimiento y diseño de expansión.

Sin duda la problemática en Europa es muy distinta a la que pueden tener regiones con crecimientos emergentes como pueden ser Sudamérica o África, incluso muchas regiones de Asia. Las economías emergentes en las cuales este proceso se está produciendo, tienen la oportunidad de aplicar todas las estrategias que ha sido efectivas en otros lugares y rechazar las políticas urbanísticas y ecológicas que se han demostrado ineficientes.

Un diseño de crecimiento urbano con una buena planificación puede traducirse no sólo en una mejora en la calidad de vida de los habitantes de las ciudades sino también en una coexistencia más armónica con los elementos naturales que pueden coexistir con estos entornos.

Otro elemento que se suele olvidar es que no todo el éxito radica en la planificación sino también en la gestión. Prácticas más sostenibles, gestión más eficiente de los recursos o fomento de determinadas especies o comunidades, pueden suponer un avance considerable en la preservación de la biodiversidad sin necesidad de emplear grandes recursos económicos.

Terr@Plural -Vivimos en el Planeta Ciudad. El futuro es urbano, pero probablemente la distopía presentada en la película clásica de ciencia ficción Blade Runner (jcuya historia tiene lugar en 2019!) No se materializará. ¿Cómo vislumbra el crecimiento de las ciudades a lo largo del siglo XXI? ¿Alcanzaremos los objetivos aparentemente inconciliables de desarrollo urbano, conservación de la biodiversidad urbana y disminución de la huella ecológica de las ciudades?

La tendencia general de los planes de urbanismo y la gestión de la biodiversidad al menos en nuestro contexto socio económico (Unión Europea) me hace ser optimista al respecto. Cada vez más ciudadanos son más conscientes, no solo de la necesidad de crear un clima de coexistencia armónica con el resto de los organismos que comparten el entorno urbano, sino del gran beneficio que supone para ellos el fomento de determinadas especies, espacios y prácticas.

Desgraciadamente, otros contextos priorizan otros elementos y el fomento de la biodiversidad y el desarrollo sostenible pasa a un segundo plano, frente a políticas encaminadas a la producción o al desarrollo lo más rápido posible en el menor tiempo. 
Terr@Plural - ¿Los conocimientos que usted ha producido sobre Ecología Urbana son de algún modo traducidos en planificación y gestión? En su país, ¿hay una cooperación efectiva entre gestores, para aplicar la ecología urbana a la planificación?

Nuestra labor como científicos consiste no solo en proporcionar evidencias y herramientas que puedan diagnosticar los problemas y realizar predicciones sobre el futuro sino además proporcionar herramientas que los gestores puedan utilizar de manera eficiente para desarrollar sus políticas de gestión y evaluar de manera objetiva e incuestionables sus actuaciones.

Cada vez más los gestores comprenden la necesidad de una cooperación entre el mundo científico para desarrollar esas herramientas, el mundo de la gestión para aplicarlas y el mundo académico para difundirlas. En este aspecto también en nuestro país se está produciendo un cambio de actitud a todos los niveles y cada uno de los elementos valora de manera adecuada a los otros.

Terr@Plural -La diversidad biológica de las ciudades es uno de los temas centrales de investigaciones de los ecologistas urbanos. ¿Cómo los ciudadanos comunes pueden ser comprometidos en acciones de conservación de la biodiversidad urbana?

La responsabilidad del ciudadano es grande, no sólo como elemento pasivo que recibe tanto las políticas de gestión como los resultados de las mismas, sino que debe ser responsable y conocer para poder conservar. Esto no implica un estudio por parte de todos los ciudadanos, pero si un compromiso respecto a que labores pueden realizar para convertirse en actores de la biodiversidad.

Iniciativas de ciencia ciudadana o de participación social, hacen que todos los individuos que habitan en una ciudad se conviertan en actores de estas políticas. Sin embargo, la labor del ciudadano no debe equivocarse, y debe estar planificada y tutorizada por personal adecuadamente formado y capacitado que además deben ser los encargados de analizar e interpretar los resultados que se puedan obtener con estas iniciativas.

\section{Terr@Plural -¿Cuál es el futuro de la ecología urbana?}

En un mundo progresivamente más urbano, el futuro apunta a un crecimiento de esta ciencia y una diversificación en sus ramas e interpretaciones. Campos tan diversos como la ecología ambiental, la biodiversidad urbana, la ecofisiología, la contaminación ambiental e incluso la epigenética deben abordar enfoques y preguntas no sólo relacionadas con sistemas y modelos naturales sino con interacciones e incluso adaptaciones exclusivas de medios urbanos y de sus áreas de solapamiento con zonas naturales. 